\title{
Ribonucleic acid and the acquisition of instrumental conditioning in rats
}

\author{
HÉLÈNE MATTE-GRENIER and \\ GERARD MALCUIT, Université Laval, \\ Quebec, Canada
}

In this experiment a study was made on the effect of ribonucleic acid with a continuous reinforcement schedule. The rats pretreated with RNA showed a faster rate of learning and greater instrumental activity than those pretreated with a saline solution. Both groups attained the extinction criterion at the same time. It seems, therefore, that a more precise knowledge of the action of RNA in learning situations can be gained by using various reinforcement schedules. number of possible reinforcements. It appears, therefore, that RNA would influence significantly the behavior of rats subjected to that reinforcement schedule.

The experiment described here was based on a continuous reinforcement schedule and intended to study the effect of RNA on the performance of rats in this simpler experimental situation. To the author's knowledge, no positive results have so far been reported, using this program.

\section{METHOD}

The Ss were 20 female albino rats, weighing from 235 to $250 \mathrm{~g}$ at the beginning of the experiment. A preliminary test, consisting of 10 trials in a simple three-alley maze, was used in order to form two correlated groups of 10 rats. The groups were made according to the three following criteria: mean speed for the run, performance at the last session, and performance in a retest.

Daily injections were started 2 weeks prior to the onset of the experiment proper and continued for 5 days a week throughout the entire period of experimentation.

Experimental rats were given $160 \mathrm{mg} / \mathrm{kg}$ RNA (yeast extract) administered intraperitoneally in a $10 \%$ neutral solution. Control rats were similarly injected with normal saline. Injections were administered after all animals were tested, approximately $15 \mathrm{~h}$ before the subsequent session.

The apparatus used during the experiment was a Grason-Stadler Skinner box

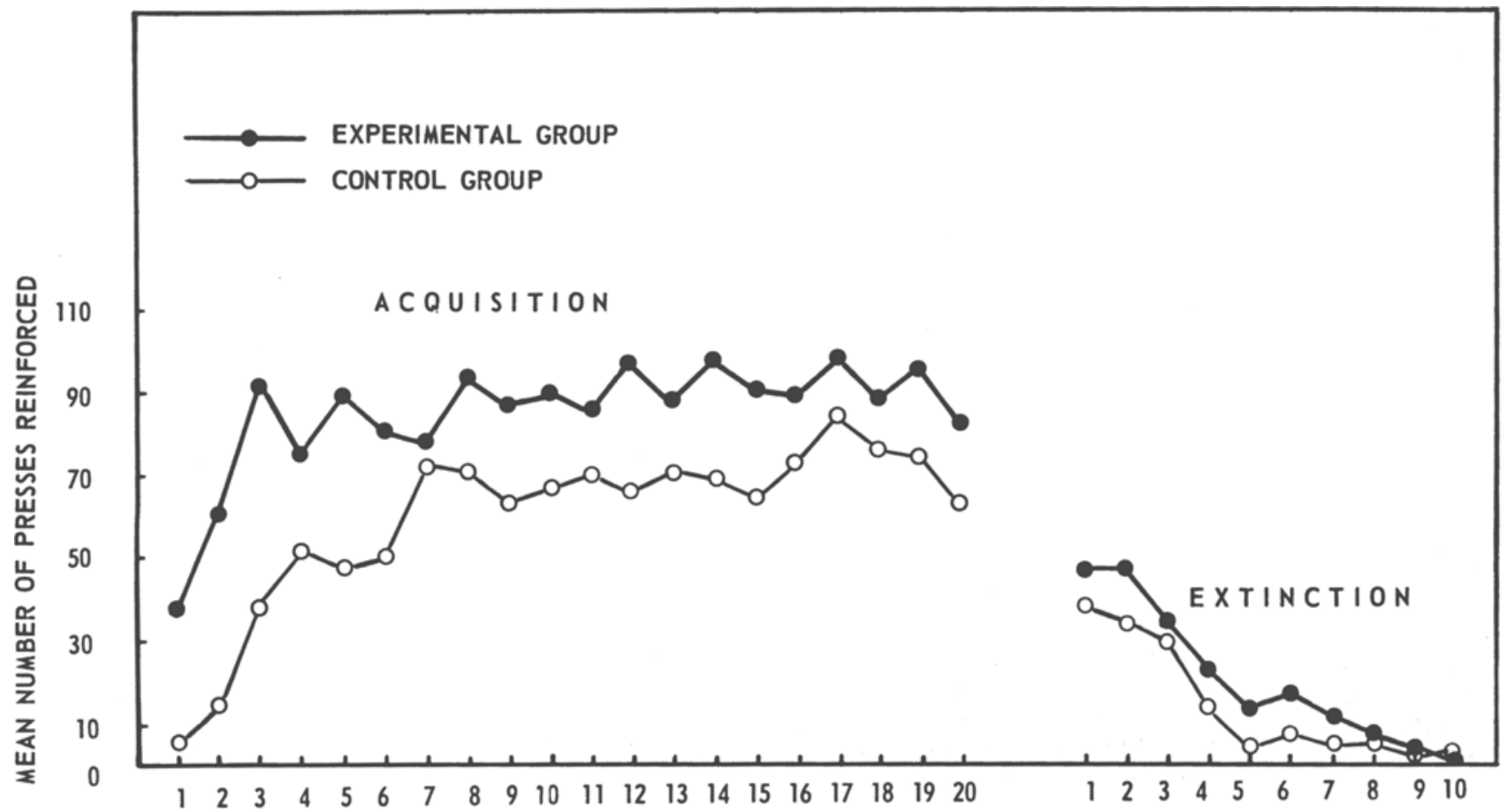

SESSION S

Fig. 1. Mean number of reinforced presses made by the two groups during sessions of acquisition and extinction. 


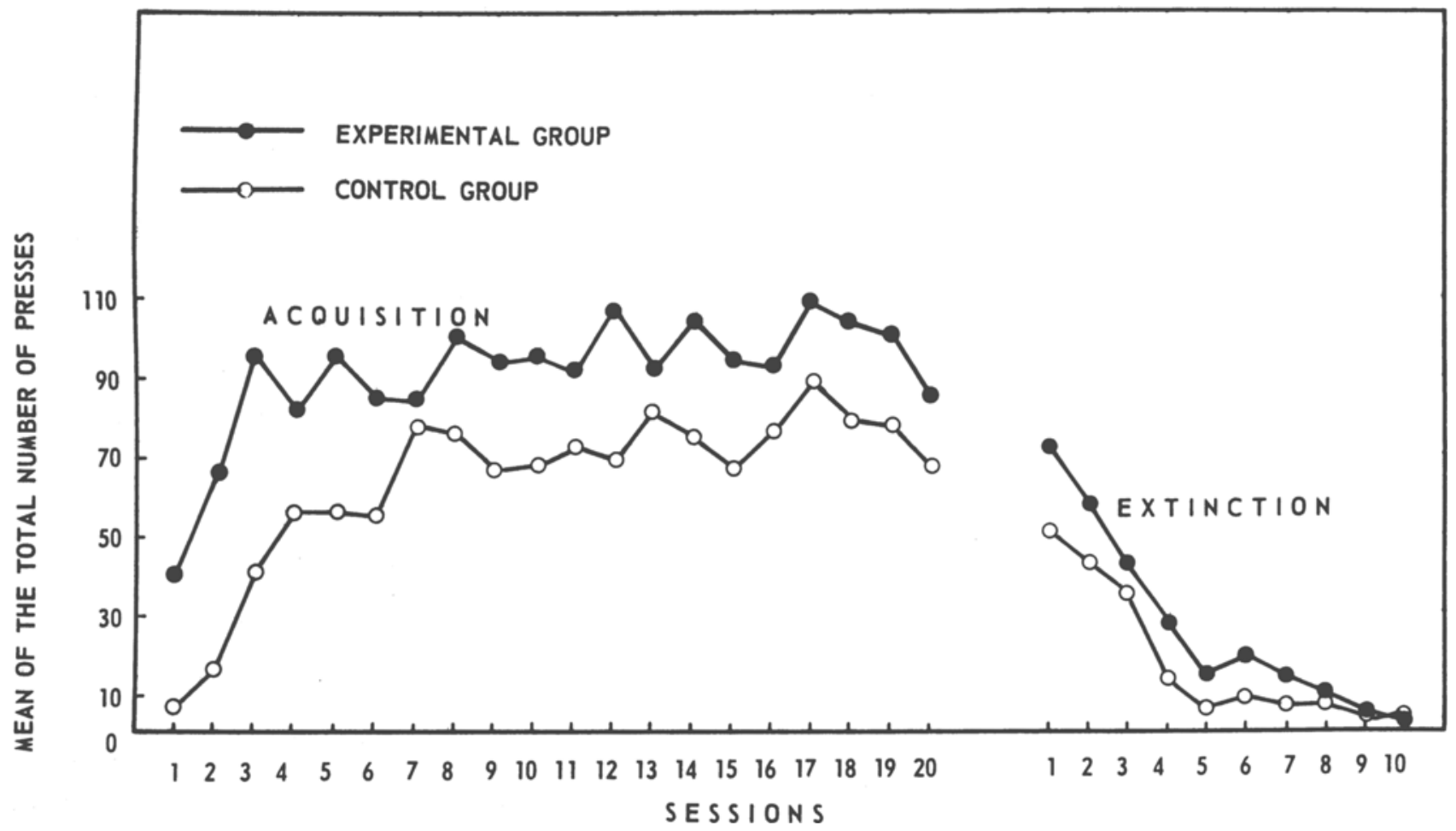

Fig. 2. Mean of the total number of presses made by the two groups during sessions of acquisition and extinction.

(E3125D). An automatic counter and timer recorded the response and reinforcement parameters. Each rat was magazine trained until it reached a criterion of one press on the lever in the course of a 15-min session. All animals were then submitted to the continuous reinforcement schedule. The reinforcement was $0.1 \mathrm{cc}$ of water and access to the water was maintained for $2 \mathrm{sec}$. Training was carried on until the two groups reached an asymptotic level, that is, a consistent performance over a 12- to 15-day period. Rats from each group were tested alternately. The extinction phase took place immediately afterward, and continued until lever-pressing returned to a low operant level (less than five responses per 15-min session).

All rats were submitted to a $23-h$ water deprivation schedule. Thirty minutes after their individual daily session, they were given water for $1 / 2 \mathrm{~h}$.

\section{RESULTS}

The data appearing in Fig. 1 indicate a better performance of the experimental group over the entire learning period. The Mann-Whitney U test (Siegel, 1956) reveals a significant difference between the two groups $(p=0.000)$. There is also a significant difference between the performances of the two groups $(\mathrm{p}<0.025)$ in 14 sessions out of 20 . The analysis of variance showed a constant performance level of the RNA-treated animals from the third session on, while the saline-treated rats took seven sessions to reach their asymptotic level. Since a t test revealed no significant difference in the mean number of reinforcements during the shaping phase, this factor cannot be invoked to explain the better performance of the experimental group.

Figure 1 also illustrated that the experimental group maintained a greater mean number of presses than the control group during the extinction phase. Yet, the two groups reached the extinction criterion at the same time and the differences between the rates of pressing were not statistically significant.

Figure 2 shows a pattern similar to the one appearing in Fig. 1. It indicates that the experimental rats did not make more useless presses (without reinforcements) than did the control group. The ratio reinforcements/total number of presses is almost the same for the two groups, 0.94 and 0.95 .

No correlation was found between the performances in the maze and in the Skinner box.

\section{DISCUSSION}

The results obtained indicate a very significant difference between the performances of the two groups during the acquisition stage which lasted 20 days.

First of all, a more rapid rate of learning was noticeable in the case of the rats pretreated with RNA. Brown (1966) and Solyom et al (1966) using the VI schedule did not find a similar effect. In the case of the present experiment, the experimental group, as compared to the control group, adopted a higher rate from the first session. Furthermore, the RNA rats reached their asymptotic level at the third session, while those of the control group only attained theirs by the seventh.

The experimental group revealed a greater instrumental activity at each session. Moreover, this activity remained well adapted to the situation since the supplementary lever-pressing was followed by further reinforcements. Lastly, the number of useless (not reinforced) presses recorded by the experimental group was not greater than that registered by the control group.

In the extinction phase, the two groups reached the criterion of five presses or less at the same time, namely, at the 10th session. Resistance to extinction did not appear to be greater, therefore, among the rats pretreated with RNA.

The use of a continuous reinforcement schedule in this experiment has permitted to show a differential effect of the RNA depending upon the experimental conditions created by the reinforcement schedule.

\section{REFERENCES}

BROWN, H. Effect of ribonucleic acid (RNA) on the rate of lever pressing in rats. Psychological Record, 1966a, 16, 173-176.

BROWN, H. Effect of ribonucleic acid (RNA) on reversal of a probability matching problem in pigeons. Psychological Record, 1966b, 16, $411-448$.

SIEGEL, S. Nonparametric statistics for the behavioral sciences. New York: McGraw-Hill, 1956.

SOLYOM, L., BEAULIEU, C., \& ENESCO, E. The effect of RNA on the operant conditioned behavior of white rats. Psychonomic Science, 1966, 6, 341-342. 